\title{
Erosion and deposition in the JET divertor during the first ILW campaign
}

M. Mayer ${ }^{1}$, S. Krat ${ }^{1,2}$, W. Van Renterghem ${ }^{3}$, A. Baron-Wiechec ${ }^{4}$, S. Brezinsek ${ }^{5}$, I. Bykov ${ }^{6}$, P. Coad $^{4}$, Yu. Gasparyan ${ }^{2}$, K. Heinola ${ }^{4,7}$, J. Likonen ${ }^{8}$, A. Pisarev ${ }^{2}$, C. Ruset ${ }^{9}$, G. de SaintAubin $^{1}$, A. Widdowson ${ }^{4}$ and JET Contributors*

EUROfusion Consortium, JET, Culham Science Centre, Abingdon, OX14 3DB, UK

${ }^{1}$ Max-Planck-Institut für Plasmaphysik, Garching, Germany

${ }^{2}$ National Research Nuclear University MEPhI, Moscow, Russia

${ }^{3} \mathrm{SCK} \cdot \mathrm{CEN}$, The Belgian Nuclear Research Centre, Boeretang 200, 2400 Mol, Belgium

${ }^{4}$ Culham Centre for Fusion Energy, Culham Science Centre, Abingdon, UK

${ }^{5}$ Forschungszentrum Jülich GmbH, Jülich, Germany

${ }^{6}$ Fusion Plasma Physics, Royal Institute of Technology, Stockholm, Sweden

${ }^{7}$ University of Helsinki, Finland

${ }^{8}$ VTT Technical Research Centre of Finland, Finland

${ }^{9}$ National Institute for Laser, Plasma and Radiation Physics, Bucharest, Romania

*See the Appendix of F. Romanelli et al., Proceedings of the $25^{\text {th }}$ IAEA Fusion Energy Conference 2014, Saint Petersburg, Russia

\begin{abstract}
Erosion and deposition were studied in the JET divertor during the first JET ITER-like wall campaign 2011-2012 using marker tiles. An almost complete poloidal section consisting of tiles $0,1,3,4,6,7,8$ was studied. The data from divertor tile surfaces were completed by the analysis of samples from remote divertor areas and from the inner wall cladding. The total mass of material deposited in the divertor decreased by a factor of 4-9 compared to the deposition of carbon during all-carbon JET operation before 2010. Deposits in 2011-2012 consist mainly of beryllium with 5-20 at.\% of carbon and oxygen, respectively, and small amounts of $\mathrm{Ni}, \mathrm{Cr}, \mathrm{Fe}$ and $\mathrm{W}$. This decrease of material deposition in the divertor is accompanied by a decrease of total deuterium retention inside the JET vessel by a factor of 10-20. The detailed erosion/deposition pattern in the divertor with the ITER-like wall
\end{abstract}


configuration shows rigorous changes compared to the pattern with the all-carbon JET configuration.

\section{Introduction}

Plasma-facing components (PFCs) in fusion devices are eroded by physical and chemical sputtering due to impact of neutral particles and ions from the plasma with energies ranging from thermal energies to several $\mathrm{keV}$. Eroded atoms can be promptly redeposited close to the place where they have been released, or they can be transported into the scrape-off layer and can potentially enter the central plasma, until they are eventually redeposited at some place in the machine. This process of erosion/re-deposition can be repeated several times resulting in a multi-step transport, until the atoms finally come to rest somewhere in the machine. Such net deposition-dominated areas show the growth of mixed films consisting typically of all elements present in the machine together with hydrogen isotopes [1]. The accumulation of hydrogen isotopes in these films by codeposition can result in the build-up of large fuel inventories inside the vacuum vessel, which makes this an important question for radiological safety if tritium is used as fueling gas [2].

During operation of JET with all-carbon walls (JET-C) massive redeposition of carbon with some beryllium and nickel, chromium and iron from Inconel components was observed in the whole inner divertor, some fraction of the outer divertor, and in remote divertor areas $[3,4,5]$. Maximum thicknesses of redeposited layers were more than $1 \mathrm{~mm}$ after several years of plasma operation [4]. This massive carbon deposition was accompanied by a high retention of hydrogen isotopes trapped in these layers.

The adhesion of redeposited layers to their substrate can be weak, resulting in flaking-off of these layers from the substrate after having reached some critical thickness. This finally results in the formation of dust, which is an issue both from the viewpoints of machine operation and safety $[2,4,6]$.

These observations of very high fuel retention in JET-C with all-carbon walls, together with investigations at ASDEX Upgrade with carbon walls and combined with detailed laboratory studies, resulted in the decision of ITER to abandon carbon and to use beryllium and tungsten as PFC materials. ASDEX Upgrade could already demonstrate, that in a full tungsten machine the retention of hydrogen isotopes decreases by about one order of magnitude compared to full carbon $[7,8]$. The ITER material mix with beryllium components in the main chamber 
and tungsten in the divertor, however, has not been tested up to now in any fusion device due to the toxicity of beryllium and the resulting difficult handling of a beryllium-containing machine. During the shutdown 2010-2011 all PFCs in JET were exchanged from carbon to either beryllium or tungsten [9], resulting in the ITER-like wall of JET (JET-ILW). Important aims of the JET-ILW experiment are the investigation of the plasma performance of this material mix and the investigation of material erosion, deposition and fuel retention.

This paper is organized as follows: Section 2 introduces the JET vessel and divertor. Section 3 summarizes the main findings about carbon erosion, redeposition and fuel retention obtained during the JET-C operational phases, with some focus on the JET divertor. Section 4 describes the plasma operation during the first ILW campaign 2011-2012, provides experimental details of the analysis of marker samples retrieved during the shutdown 2012, and presents the results from the JET-ILW divertor. Material cycles during JET-C and JETILW are discussed in Section 5.

\section{The JET vessel}

A cross-section through the JET vessel during the first JET-ILW campaign is shown in Fig. 1, the divertor is detailed in Fig. 2. The inner vessel wall consists of 16 poloidal inner wall guard limiters (IWGL) and the inner wall cladding (IWC) in between these limiters. The IWC is recessed by a few centimeters behind the IWGLs, see for example Fig. 2 in [9]. The outer vessel wall is a very heterogeneous area with large ports. Large fractions of the wall are recessed far behind the outer poloidal limiters (OPLs) or antennae limiters. IWGL and OPL tiles are made from bulk beryllium, the IWC consists of Be coated Inconel and W-coated tiles used for the NBI shine-through areas and restraint rings. The upper part of the vessel is protected by the upper dump plate (UDP) made from bulk Be. The inner divertor consists of tiles $0,1,3$, and 4 (see Fig. 2), the outer divertor of tiles 5, 6, 7, 8, and 9. The divertor is composed of bulk W tiles for the horizontal target tile 5 and $\mathrm{W}$-coated $\mathrm{CFC}$ tiles for all other tiles [9].

The JET vessel and divertor had a very similar shape during the last JET-C campaign 20082009 , except that all plasma-facing materials consisted of carbon, typically as carbon fibre composite (CFC) material. Regular beryllium evaporations were used for wall conditioning. 


\section{Carbon erosion and redeposition in JET-C during the discharge period 2008-2009}

Global carbon erosion and deposition patterns in JET-C have been studied extensively in the last discharge period 2008-2009 before installation of the JET-ILW [10, 11]. From the viewpoint of wall analysis this is the best-investigated operational period, the results are summarized below. Global carbon erosion/deposition patterns for earlier discharge periods are described e.g. in $[12,13]$, but the results for earlier discharge periods generally suffer from a limited number of analyzed samples from only few different wall areas. Available results from these operational periods are at least in qualitative agreement with the 2008-2009 period.

\subsection{Net carbon sources}

Net carbon sources in JET-C were identified mainly in the main chamber, see Fig. 1 for a cross-sectional view through the JET vessel. Long-term samples (LTS) at the inner wall cladding (IWC) were used regularly since the discharge period 1995 for measurements of material erosion at the IWC $[13,14,15,16]$. The IWC was a net erosion area for low-Z (beryllium and carbon), medium-Z (aluminum) and high- $Z$ (tungsten) materials during all investigated periods. The measured erosion of carbon from the whole IWC was about $4 \mathrm{~g} \mathrm{C} / \mathrm{h}$ during the discharge period 2005-2009 [15]. The IWC is recessed by a few cm behind the inner wall guard limiters (IWGL) and can be reached only by neutral particles. Carbon showed high net erosion at the IWC, its erosion exceeded that of beryllium. This can be explained only by large fluxes of neutral deuterium atoms with energies below about $40 \mathrm{eV}$ and chemical sputtering by formation of methane [15]. The inner wall guard limiters showed a complicated pattern of erosion-dominated areas at the plasma-exposed faces and depositiondominated areas at the limiter sides $[13,17]$. In total these limiters showed small net erosion $[10,11]$.

The outer JET wall is a very heterogeneous area with large ports. Large fractions of the wall are recessed far behind outboard or antennae limiters. Some erosion was observed here during the discharge period 1995 [14], but since then only little information became available. It is generally assumed that the outer wall plays only a minor role for the global erosion/deposition pattern. The outer poloidal limiters (OPL) showed a mixture of erosion-dominated areas at the plasma-facing surfaces and deposition-dominated areas at the limiter side walls [10]. The net erosion/deposition balance showed small erosion from these limiters [11]. 
The upper dump plates were reported to be a rather strong net erosion area with a carbon erosion from all dump plates of about $4 \mathrm{~g} \mathrm{C} / \mathrm{h} \mathrm{[11].} \mathrm{This} \mathrm{number} \mathrm{has} \mathrm{to} \mathrm{be} \mathrm{treated} \mathrm{with} \mathrm{some}$ care, however, because it is based on the complete vanishing of a carbon marker stripe: According to the experience at ASDEX Upgrade [18] and during tests at the high-flux facility GLADIS [19] carbon marker stripes are brittle and delaminate easily from the substrate when receiving power fluxes exceeding a few $\mathrm{MW} / \mathrm{m}^{2}$. The erosion at the upper dump plate therefore is rather uncertain and may be considerably lower, but also considerably higher than the given number. As was shown with marker stripes tiles 7 and 8 from the outer divertor are net erosion areas [20]. A total erosion of about $2 \mathrm{~g} \mathrm{C} / \mathrm{h}$ was reported for the period 2008-2009 [11].

In total net erosion areas with a total net carbon erosion of about $10 \mathrm{~g}$ carbon/h could be identified, with the largest contributions from the IWC, the upper dump plates, and the outer divertor. Additional net sources exist at the IWGLs and OPLs, but these seem to be small.

All JET plasmas start as limiter plasmas at the inner wall. Erosion in the main chamber therefore can occur either during this limiter phase of a discharge, or during the succeeding divertor phase. This is discussed in more detail in [10,21].

\subsection{Net carbon deposition}

Net carbon deposition areas in JET-C were observed mainly in the divertor. Redeposited films in JET-C consisted mainly of carbon with some beryllium due to regular beryllium evaporations and traces of nickel, chromium and iron from Inconel components. These redeposited films can contain deuterium in varying concentrations with $\mathrm{D} / \mathrm{C}$ ratios up to about one; the deuterium content depends on the deposition conditions and the temperature history of the film.

The whole inner divertor showed strong deposition of hydrocarbon films on all plasmaexposed faces of tiles 1,3 , and 4 . The thickest deposits in the inner divertor were observed on the sliding part of tile 4 and grew up to layer thicknesses of $500 \mu \mathrm{m}$ during the 2008-2009 discharge period [4]. The outer divertor showed deposits only on tile 6 . The thickest deposits were on the sliding part of this tiles and reached thicknesses up to about $500 \mu \mathrm{m}$ during the 2008-2009 discharge period [4]. Tiles exposed from 1998-2009 showed deposited layers with thicknesses even up to $1200 \mu \mathrm{m}$ [4]. The total deposition of carbon on divertor tiles was $200-$ $800 \mathrm{~cm}^{3}$ during the $2008-2009$ period [4, 10]. The large uncertainty is due to observed differences between old tiles exposed 1998-2009 and new tiles exposed 2008-2009 [4]. 
Assuming a mass density of $1 \mathrm{~g} / \mathrm{cm}^{3}$ this converts to a deposition rate on divertor tiles of 6-24 g carbon $/ \mathrm{h}$.

Hydrocarbon layers deposited on tiles 4 and 6 can decompose thermally during ELM impacts to hydrocarbon radicals, which can be ejected towards remote divertor areas and can redeposit there $[22,5]$. Thick hydrocarbon layers with high $\mathrm{D} / \mathrm{C}$ ratios are found in remote areas of the inner and outer divertor on the louvers and the carrier structure [10]. Layers corresponding to a deposition rate of about $4 \mathrm{~g}$ carbon/h were formed during the 2008-2009 campaign on the ribs of the carrier structure [10]. Hydrocarbon layers formed on divertor tiles or in remote areas can flake off their substrate, resulting in the formation of dust. Dust was collected by hoovering in the whole divertor, corresponding to a dust formation rate of about $7.5 \mathrm{~g}$ carbon/h.

As already discussed in section 2.1 some carbon deposition was also observed at the side faces of main chamber limiters. These are, however, small compared to the deposition in the divertor and in remote areas. The total carbon accumulation rate in form of layers on divertor tiles in remote divertor areas, and in form of dust, is about 17-36 $\mathrm{g}$ carbon/h. This is a factor of 2-4 larger than the amount of carbon released from identified carbon sources. This points either towards unidentified additional carbon sources, or large systematic errors.

\section{Divertor erosion and deposition in JET-ILW during 2011-2012}

\subsection{Experimental}

During the discharge period 2011-2012 in total 2819 successful discharges (with a plasma current above 0.7 MA) were performed with a discharge time of $19000 \mathrm{~s}$ (5.3 h) in limiter configuration and $45100 \mathrm{~s}(12.5 \mathrm{~h})$ in divertor configuration. A large variation of discharge types was performed. The inner strike point was usually on tile 3 and the outer strike was usually on tile 5, see Figs. 1 and 2, but different configurations (for example with strike points on tiles 4 and 6) were also performed. Typically stable type-I ELMy H-modes with low and high triangular shape were performed with $2.0 \mathrm{MA} / 2.1 \mathrm{~T}$ and $2.5 \mathrm{MA} / 2.7 \mathrm{~T}$ and neutral beam injection of typically $15 \mathrm{MW}$ for 4-5 s. The discharge period 2011-2012 can be roughly divided into 3 phases: 4 months of low-power operation, followed by 4 months of development of H-mode scenarios, and finally 6 weeks of high-power operation [23]. Only a limited set of high current pulses was performed and achieved H-mode pulses up to 3.5 MA/3.2 T with combined Neutral Beam (NBI) and Ion Cyclotron Resonance (ICRF) 
heating in the range of 24-26 MW [24,25]. Compared to JET-C, where plasmas up to 4.5 MA were performed, the input power during the first two phases of JET-ILW 2011-2012 was lower and reached comparable levels as in JET-C only during the last high-power operational phase [26]. The ELM frequency was always kept above about $10-20 \mathrm{~Hz}$, the temperature of the bulk tungsten tile 5 was kept below $1200^{\circ} \mathrm{C}$. Operation with JET-ILW required a significant amount of deuterium puffing with a rate above $10^{22} \mathrm{D}$-atoms/s [25].

All positions on divertor tiles are described using the s-coordinate system, see Fig. 2. The scoordinate starts in the upper left corner of tile 0 and follows the tile surfaces from the inner to the outer divertor.

All JET divertor tiles except tile 5 consist of carbon fiber composite (CFC) coated with 10$20 \mu \mathrm{m}$ tungsten on the plasma-facing surfaces [27]. A set of special marker tiles consisting of tiles $1,4,6,7,8$ was further coated with a tungsten marker layer with a thickness of about 3 $\mu \mathrm{m}$ with a $3 \mu \mathrm{m}$ thick molybdenum interlayer between the tungsten marker layer and the thick tungsten coating [28]. The tungsten marker layer allows determining erosion of tungsten as well as the quantitative determination of deposition of all elements; the Mo interlayer is necessary for distinguishing the $\mathrm{W}$ marker layer from the $\mathrm{W}$ coating for depth profiling methods. Tile 0 was a regular tile containing a $10-15 \mu \mathrm{m} \mathrm{W}$ coating including a Mo interlayer of 2-3 $\mu \mathrm{m}$ between the $\mathrm{W}$ layer and the CFC substrate. This tile therefore allows only the determination of deposition. Tile 3 was without the tungsten marker layer and had the molybdenum layer on top. This tile was initially foreseen for studying tungsten redeposition and was retrieved erroneously instead of a Mo/W coated tile.

Prior to installation in JET the thicknesses of the marker layers were analyzed using nondestructive ion-beam analysis methods analyzing whole tiles. After exposure of the tiles inside JET samples with a diameter of $18 \mathrm{~mm}$ were cut from the tiles. These samples were analyzed using a glove-box due to the toxic beryllium content. The marker coating thickness homogeneity in toroidal direction was measured on tiles 3 and 7 (which are the longest) and was better than $10 \%$ over a toroidal distance of $20 \mathrm{~cm}$. The measurements before and after were only a few $\mathrm{cm}$ apart in toroidal direction, so that the thickness variation due to the different toroidal positions is assumed to be below $3 \%$.

Tile 5 consists of bulk tungsten lamellas [29]. 12 lamellas were coated with $\mathrm{Mo} / \mathrm{W}$ marker layers and have been pre-characterized, but will become available for analysis only later in 2015. 
Layer thicknesses were determined using Rutherford backscattering (RBS) with $3 \mathrm{MeV}$ incident protons. For tiles 0 and 1, where very thick deposits were observed, in addition 3.8 $\mathrm{MeV}$ and $4.5 \mathrm{MeV}$ protons were used. Details of all ion-beam analysis measurements can be found in [30]. Nuclear reaction analysis (NRA) was used to measure the amounts of $\mathrm{D}, \mathrm{Be}$ and $\mathrm{C}$ with ${ }^{3} \mathrm{He}$ ions at energies up to $4.5 \mathrm{MeV}$. The $\mathrm{D}\left({ }^{3} \mathrm{He}, \mathrm{p}\right)^{4} \mathrm{He}$ reaction was used to measure the $\mathrm{D}$ content. The ${ }^{12} \mathrm{C}\left({ }^{3} \mathrm{He}, \mathrm{p}_{0}\right){ }^{14} \mathrm{~N}$ and ${ }^{12} \mathrm{C}\left({ }^{3} \mathrm{He}, \mathrm{p}_{1}\right){ }^{14} \mathrm{~N}$ reactions were used to measure the ${ }^{12} \mathrm{C}$ content, and the ${ }^{9} \mathrm{Be}\left({ }^{3} \mathrm{He}, \mathrm{p}_{0}\right){ }^{11} \mathrm{~B}$ and ${ }^{9} \mathrm{Be}\left({ }^{3} \mathrm{He}, \mathrm{p}_{1}\right){ }^{11} \mathrm{~B}$ reactions for measuring the Be content. For thin deposits the NRA data provide more sensitive and accurate results for $\mathrm{Be}$ and $\mathrm{C}$ than the RBS data, which were used in case of thick deposits. The SIMNRA code with SRIM 2013 stopping power was used for quantitative evaluation of the RBS and NRA spectra, the surface roughness was taken into account approximately. RBS measurements of $\mathrm{W}$ and Mo layer thicknesses are accurate within about 5\% for erosion areas and thin deposits. For thick deposits total amounts of deposited elements can be determined with an accuracy of about $10-20 \%$ from the RBS data. The amount of $\mathrm{D}$ can be determined with an accuracy of about $10 \%$ from the NRA data, while Be and $\mathrm{C}$ can be measured with an accuracy of $20-30 \%$ with NRA. The detection limits of NRA are about $10^{15} \mathrm{D}$-atoms $/ \mathrm{cm}^{2}$ and about $10^{16} \mathrm{Be}$ or Catoms $/ \mathrm{cm}^{2}$. See [30] for details.

All analysed divertor tiles are from the same toroidal position. Based on the visual impression the erosion/deposition pattern from tile to tile is rather homogeneous in toroidal direction, but more quantitative investigations of the toroidal symmetry in the divertor have not been performed. Toroidal symmetry of the erosion/deposition pattern has been demonstrated for the inner wall cladding using long-term samples, see $[15,16]$.

\subsection{Results}

The thicknesses of the $\mathrm{W}$ and Mo marker layers before and after exposure and the deposition of $\mathrm{C}, \mathrm{Be}$ and $\mathrm{D}$ in the divertor are shown in Figure 3. The lowest graph shows the distribution of inner and outer strike points of the divertor phases of successful discharges during the 2011-2012 campaign. A cross-section of the divertor is shown in Fig. 2 together with tile numbers and characteristic points with corresponding s-coordinate.

The outer strike point was never on tile 8 and comparatively seldom on tile 7, see Fig. 3. Tiles 8 and 7 showed only very minor modifications due to the plasma exposure. The thicknesses of the $\mathrm{W}$ and Mo marker layers were identical before and after exposure, i.e. the $\mathrm{W}$ marker layer 
was not eroded within the experimental uncertainty of about $200 \mathrm{~nm}$. Because the Mo layer is located below the $\mathrm{W}$ layer, the thickness of this layer should remain unchanged and can be used as a check of correct data processing. The absence of tungsten erosion on these tiles is noteworthy, because tungsten marker stripes exposed during the discharge campaign 20012004 showed strong erosion of several $\mu \mathrm{m}$ tungsten on tiles 7 and 8 [20]. During the 20012004 campaign an often-used plasma configuration was with the outer strike point on tile 7. This tile therefore showed strong erosion at the strike point regions. However, strong erosion was also observed on the outer baffle and apron of tile 8 [20], even though the strike point was hardly ever placed there. This erosion did not occur during the 2011-2012 campaign. This might be due to the different outer strike point positioning, which was regularly on the vertical tile 7 in 2001-2004 but usually on tile 5 in 2011-2012. Another possible reason might be the decreased plasma impurity content in 2011-2012 (and especially the decrease of carbon and oxygen) [21, 31, 32], which results in decreased tungsten sputtering by impurities. However, as has been shown in [33], tungsten erosion in the outer divertor is mainly due to impact of ELMs, so that a decrease of the impurity content should have only a minor effect.

Smaller amounts of Be, C, and D were observed on the surfaces of tiles 7 and 8 at all measured points. The amounts of $\mathrm{C}, \mathrm{Be}$ and $\mathrm{D}$ rise steadily towards the bottom of the tiles, the amount of $\mathrm{D}$ varies from $1.4 \cdot 10^{17}$ atoms $/ \mathrm{cm}^{2}$ to $2.7 \cdot 10^{17}$ atoms $/ \mathrm{cm}^{2}$. Be and $\mathrm{C}$ are observed at the surface. Most of the D is also at or close to the surface, but some indications for deeper diffusion of $\mathrm{D}$ in the $\mathrm{W}$ layer were observed [30]. However, this is hard to interpret due to the very large surface roughness o the tiles.

On tile 6, see Fig. 3, the thickness of the W layer increased after exposure by about $500 \mathrm{~nm}$, while the Mo layer thickness was identical within the experimental uncertainty before and after exposure. The adjacent bulk tungsten tile 5 is a net tungsten erosion area. Tungsten eroded on tile 5 and redeposited on tile 6 might explain the increased amount of tungsten on tile 6. However, the very homogeneous increase of the $\mathrm{W}$ layer thickness remains mysterious. The maximum deposition of $\mathrm{Be}, \mathrm{C}$ and $\mathrm{D}$ is observed at the central sloped part of tile 6 . Maximum deposited amounts are $6 \cdot 10^{18} \mathrm{Be}$-atoms $/ \mathrm{cm}^{2}, 4 \cdot 10^{18} \mathrm{C}$-atoms $/ \mathrm{cm}^{2}$, and $2 \cdot 10^{18} \mathrm{D}$ atoms $/ \mathrm{cm}^{2}$. The outer strike point was located close to the position of maximum deposition in a number of discharges. SEM investigations show a very inhomogeneous deposition of the light elements on the surface with deposition dominantly in the valleys of the rough surface, see Fig. 5. 
Tile 5 consists of 4 stacks A - D of bulk tungsten lamellas [29]. Stack A faces the inner and stack D the outer divertor. The outer strike point was usually positioned on stacks B, C or D, with the strike point residing most often on stack C. A photographic view of stacks B - D after removal of tile 5 from the JET vessel is shown in Fig. 5. According to the optical impression the tile surfaces look very clean and shiny and show no visible deposits. This indicates that tile 5 is a net erosion area. This is supported by spectroscopic investigations, which show emission of WI light from tile 5 during the whole discharge campaign $[32,33]$ : This means that tungsten atoms are still present at the surface, i.e. the surface is not fully covered by different elements. The marker lamellas from tile 5 did not become available for analysis until May 2015, so more quantitative results from surface analysis are not yet available. Some marker lamellas on stacks C and D show visible damage, see Fig. 5.

Tile 4 shows no measurable erosion of the $\mathrm{W}$ marker layer and some deposition of $\mathrm{Be}, \mathrm{C}$ and W. The maximum deposition is observed at the central sloped part with maximum deposited amounts of $3 \cdot 10^{18} \mathrm{Be}$-atoms $/ \mathrm{cm}^{2}, 4 \cdot 10^{18} \mathrm{C}$-atoms $/ \mathrm{cm}^{2}$, and $2 \cdot 10^{18} \mathrm{D}$-atoms $/ \mathrm{cm}^{2}$. As on tile 6 the deposition of the light elements was very inhomogeneous with deposition dominantly in the valleys of the rough surface. The deposited layers were very inhomogeneous in thickness which ranged from $0-5 \mu \mathrm{m}$.

Tile 3 was used in many discharges for placing the inner strike point; see Figs. 1 and 2 for a typical magnetic configuration and Fig. 3 for the histogram of strike point distributions. Unfortunately the investigated tile 3 had no W marker layer on top of the Mo interlayer: This tile was initially intended to study $\mathrm{W}$ redeposition and was retrieved erroneously instead of the W-coated tile. The upper half of the tile shows strong erosion of the Mo layer, at scoordinates around $450 \mathrm{~mm}$ the Mo has been almost completely eroded. The erosion of the Mo layer was confirmed by depth-profiling using Glow-Discharge Optical Emission Spectroscopy (GDOES) [34]. The observed erosion is correlated with the distribution of strike points, but shifted upwards by about $30 \mathrm{~mm}$. Spectroscopic investigations from a regular Wcoated tile show emission of WI light from the inner strike point on tile 3, indicating that not only erosion of Mo, but also erosion of $\mathrm{W}$ takes place on tile 3 [32]. This erosion is accompanied by deposition of $\mathrm{W}, \mathrm{Be}$ and $\mathrm{C}$. W originates from neighboring $\mathrm{W}$-coated divertor tiles and $\mathrm{Be}$ from the main chamber. The amount of $\mathrm{D}$ on tile 3 is relatively small.

Three main areas can be differentiated on the surface of tile 1 . The lower half of the tile (scoordinates from $\approx 350 \mathrm{~mm}$ to the bottom of the tile) is an area of net $\mathrm{W}$ erosion. The erosion is relatively small and at the border of the RBS sensitivity, but could be confirmed in cross- 
sections by electron microscopy [30]. In addition to erosion of the $\mathrm{W}$ marker layer, some deposition of $\mathrm{Be}, \mathrm{C}$ and $\mathrm{D}$ can be observed. The area from $\mathrm{s} \approx 300 \mathrm{~mm}$ to $\mathrm{s} \approx 350 \mathrm{~mm}$ shows neither erosion nor thick deposition. A large number of small particles were observed deposited on the surface. This area can be considered as intermediate between the lower area with $\mathrm{W}$ erosion and the upper area with thick deposits. The sliding and horizontal ("apron") parts of tile 1 are areas with very thick deposits. Deposits of up to $10^{20}$ atoms $/ \mathrm{cm}^{2}$ of Be are observed here. The deposits form flaky films having a complex multilayered structure [11] representing the discharge and operational history of the machine, see Fig. 6. The deposits consist of Be, C, D, W and $\mathrm{O}$. The average composition of the film was $70-80$ at.\% of Be, 710 at. $\%$ of $\mathrm{O}, 10-15$ at. $\%$ of $\mathrm{C}$, about 3 at. $\%$ of $\mathrm{W}$ and $1-5$ at. $\%$ of $\mathrm{D}$.

Tile 0 ("high field gap closure tile", HFGC tile) has not been coated with marker layers, but a regular tile was analyzed after exposure without pre-characterizing the $\mathrm{W}$ layer thickness. The deposition pattern on the tile can be separated into two main areas - one with thick deposits (Be thickness $\sim 10^{20}$ atoms $/ \mathrm{cm}^{2}$ ) and one with thin deposits (Be thickness $1.4 \cdot 10^{18}$ atoms $/ \mathrm{cm}^{2}$ ). The area of thick deposits continues from the area with thick deposits on tile 1 and extends over about $2 / 3$ of the tile until an s-coordinate of about $\mathrm{s} \approx 73 \mathrm{~mm}$. The rest of the tile contains only thin deposits. The composition of the thick films on tile 0 is generally similar to the thick films on tile 1. The deposits consist of Be, C, D, W and O. The average composition of the film was $85-90 \% \mathrm{Be}, 3-5 \% \mathrm{C}, 7-9 \% \mathrm{O}, 0.2-0.5 \% \mathrm{~W}$. The tungsten and carbon content is lower on tile 0 than on tile 1 , while the oxygen content remains roughly the same. This indicates that the source of carbon is different than the oxygen source, which is likely oxidation of beryllium in the deposited film. A layered structure was observed in the oxygen concentration originating probably from oxidation during week-ends.

Integrating the measured amounts of deposited material by assuming toroidal symmetry it is possible to determine the total amounts of $\mathrm{Be}, \mathrm{C}$ and $\mathrm{D}$ deposited on divertor tiles during the 2011-2012 campaign, see Table 1. In total, about $52 \mathrm{~g}$ of $\mathrm{Be}, 12 \mathrm{~g}$ of $\mathrm{C}$ and $0.9 \mathrm{~g}$ of $\mathrm{D}$ were deposited in the divertor during the campaign. More than $2 / 3$ of the total deposition is found on tiles 0 and 1 .

Deposition in remote areas was determined on the outer side of silicon wafers mounted at the inner and outer louvers [5]. The atomic concentrations were $20-25$ at $\% \mathrm{C}$ and $65-45 \% \mathrm{Be}$, i.e. deposits in remote areas consist mainly of Be but contain a substantial carbon concentration. The atomic concentration of $\mathrm{D}$ in the films found in remote areas was 30-20 at $\%$. The inner divertor showed higher carbon and deuterium concentrations and a smaller total thickness of 
the deposited layers. The composition of deposits in remote areas of the inner divertor is very similar to the composition of deposits on tiles 4 , and deposits in remote areas of the outer divertor resemble deposits on tile 6 (see Table 1). The observed deposition rate in the outer divertor is higher than the deposition rate in the inner divertor, which is in good agreement with measurements using quartz micro balances $(\mathrm{QMB})$ and rotating collectors in remote areas [35]. Compared to JET-C the material deposition rate decreased by a factor of 4 (outer divertor) and 20 (inner divertor). In JET-C remote areas in the inner divertor showed a higher deposition rate and thicker deposits, while in JET-ILW the outer divertor shows the higher deposition rate. A similar observation is reported in [35] from the QMBs and rotating collectors.

\section{Discussion: From JET-C to JET-ILW}

As discussed in Section 3.1 identified net carbon sources in JET-C were mainly in the main chamber: Inner wall cladding (IWC), upper dump plates, and to a lesser extent inner wall guard limiters (IWGL) and outer poloidal limiters (OPL). Outer divertor tiles 7 and 8 were also identified as net carbon sources. Carbon influxes from these identified carbon source areas are too small by a factor of 2-4 in order to explain the observed divertor deposition, so that in addition to these identified carbon sources either non-identified additional carbon sources have to be assumed or the systematic uncertainties are much larger than supposed, see Section 3.2. The carbon erosion mechanism could be identified in detail at the IWC: Erosion at the IWC is dominated by chemical sputtering due to methane formation by impact of neutral deuterium atoms with low energies below about $40 \mathrm{eV}$, see Section 3.1. In JET-C carbon was the main plasma impurity. The carbon concentration in the plasma core was derived from the effective charge of the plasma $Z_{\text {eff }}$ and was typically $3 \%$ for diverted plasmas [21].

With installation of the JET ITER-like wall primary beryllium sources are all located in the main chamber, because the divertor consists of tungsten. The net influx of beryllium from the IWC was reduced by a factor of about 5 as compared to carbon due to the sputtering threshold of beryllium, which strongly reduces beryllium erosion at low deuterium impact energies, and by the coverage of about $1 / 3$ of the IWC by tungsten. Net beryllium erosion from the IWGLs and OPLs has proven to be small [11]. Erosion at other wall areas, for example the upper dump plates, has not been quantified. The main plasma impurity during JET-ILW 2011-2012 was beryllium with a plasma core concentration (as derived from $Z_{\text {eff }}$ ) of about $1.1 \%$ [21]: 
This is about 3 times smaller than the carbon concentration in JET-C and indicates that beryllium influxes from the main chamber have decreased not only at the IWC but have decreased globally.

The decrease of net impurity influx from the main chamber results in a corresponding decrease of the total rate of material deposition in the divertor by a factor of 4-9 in mass as compared to JET-C. This is in reasonable agreement with the observed decrease of influxes from the main chamber walls. Main deposition areas in JET-ILW are tiles 0 and 1, compared to tiles 4 and 6 with JET-C. WallDyn simulations of the beryllium transport in JET-ILW calculate beryllium erosion in the main chamber followed by transport in the scrape-off layer (SOL) and deposition of beryllium predominantly on tiles 0 and 1 [32,36,37]: These tiles intersect the SOL and are the first surfaces hit by particles flowing in the SOL. This results in high beryllium deposition rates on these tiles, in accordance with the experimentally observed deposition pattern. The global erosion/deposition pattern of carbon in JET-C has not been successfully modelled, but it is assumed that carbon transport is dominated by a multi-step process of erosion/re-deposition/re-erosion steps, see for example [38] for a model describing the transport of carbon to remote divertor areas. This multi-step process is generally more difficult to model.

In JET-ILW the deposition in remote areas of the inner and outer divertor is dominated by deposition of beryllium with a $\mathrm{Be}: \mathrm{C}$ atomic ratio of 2-3:1. Compared to the $\mathrm{Be}: \mathrm{C}$ ratio of 1020:1 in the thick deposits on tiles 0 and 1 and a Be:C ratio in the plasma core of about 10:1 carbon is enriched in the deposits found on tile 4 and in remote areas. These areas were main carbon deposition areas during JET-C operation. The transport of carbon therefore seems to be not much modified in JET-ILW compared to JET-C. Residual carbon sources in JET-ILW have not been clearly identified. JET-ILW still contains tons of carbon in form of W-coated CFC divertor tiles. Carbon can be eroded by chemical erosion due to impact of neutral D and formation of methane or by $\mathrm{O}$ atoms and formation of $\mathrm{CO}$ or $\mathrm{CO}_{2}$ from gaps between tiles or rear sides of tiles, which have not been coated with W. Other potential carbon sources might be imperfect $\mathrm{W}$ coatings with incomplete coverage of the whole CFC surface or damaged W coatings with delaminated tungsten films.

The decrease of the mass rate of deposited material by a factor of 4-9 from JET-C to JETILW is accompanied by a decrease of long-term deuterium retention by a factor of 10-20. This decrease is larger than the decrease of material deposition due to a smaller concentration of retained D in the Be-dominated deposited layers in JET-ILW compared to JET-C. 
Despite this observed decrease of material deposition rate in JET-ILW the erosion of beryllium in the main chamber is by far not negligible: Under typical JET conditions it is smaller than the erosion of carbon, but it is still high due to the comparably high physical sputtering yield of beryllium by deuterium impact. It has been already shown at the IWC that the erosion of tungsten was only about ten nm during the whole 2011-2012 campaign [16]. From the viewpoint of material erosion and redeposition a further substantial reduction of impurity influxes and resulting material redeposition could be achieved by replacing beryllium in the main chamber by tungsten.

In JET-C carbon impurity fluxes into the divertor were high enough to convert the whole inner divertor into a net deposition area. The decreased impurity influxes in JET-ILW turned the areas on tiles 1 and 3 in the vicinity of the typically used inner strike point to a net erosion area. The main erosion mechanism is assumed to be erosion by ELMs. Eroded tungsten is transported in toroidal direction and redeposited again on tile 3.

\section{Conclusions}

Erosion and deposition in the JET divertor were studied during the first JET ITER-like wall (JET-ILW) campaign 2011-2012 by using specially prepared divertor marker tiles, which were analysed before and after the campaign. The erosion/deposition pattern observed with the JET-ILW configuration shows profound changes compared to the pattern observed with JET$\mathrm{C}$ : The total material deposition rate in the divertor decreased by a factor of 4-9 compared to the deposition rate of carbon in JET-C. The highest deposition rate and the thickest deposits with layer thicknesses of up to $20-30 \mu \mathrm{m}$ is now observed on the upper and horizontal parts of the inner divertor. The deposits consist mainly of beryllium with 5-20 at.\% of carbon and oxygen, respectively, and small amounts of $\mathrm{Ni}$ and $\mathrm{W}$. The deposition rates of $\mathrm{D}, \mathrm{Be}$ and $\mathrm{C}$ decreased considerably, in particular in the inner and outer divertor corners and in remote areas. At many of these locations deposition is only observed in valleys of the rough tile surfaces. The vertical part of the inner divertor even turned from a former net deposition area into a net erosion area: Compared to JET-C this is a profound change of the inner divertor behaviour. This decrease of material deposition in the divertor is accompanied by a decrease of total deuterium retention rate inside the JET vessel by a factor of 10-20. Another set of divertor marker samples has been exposed during the second JET-ILW discharge campaign 2013-2014 which contained a substantially larger number of high-power pulses. These samples therefore will allow a comparison to the first JET-ILW campaign 2011-2012 which 
had fewer high-power and a larger fraction of low-power pulses. These samples were retrieved from the JET vessel in 2015 and will be analysed in 2016.

Despite the decrease of total material deposition rate with JET-ILW the erosion of Be in the main chamber is by far not negligible: It is smaller than the erosion of carbon, but it is still high due to the comparably high physical sputtering yield of beryllium. A further reduction of impurity influxes, resulting material redeposition and retention of hydrogen isotopes by codeposition can be probably only achieved by replacing beryllium in the main chamber by tungsten.

The observed deposition pattern of beryllium in the JET-ILW divertor is in good agreement with the deposition pattern calculated by the WalDyn code: This raises confidence in the predictions for ITER.

\section{Acknowledgements}

The technical assistance by J. Dorner and M. Fußeder with ion-beam analysis measurements and helpful discussions with R. Neu, H. Maier, K. Schmid and J.W. Coenen are gratefully acknowledged.

This work has been carried out within the framework of the EUROfusion Consortium and has received funding from the Euratom research and training programme 2014-2018 under grant agreement No 633053. The views and opinions expressed herein do not necessarily reflect those of the European Commission 


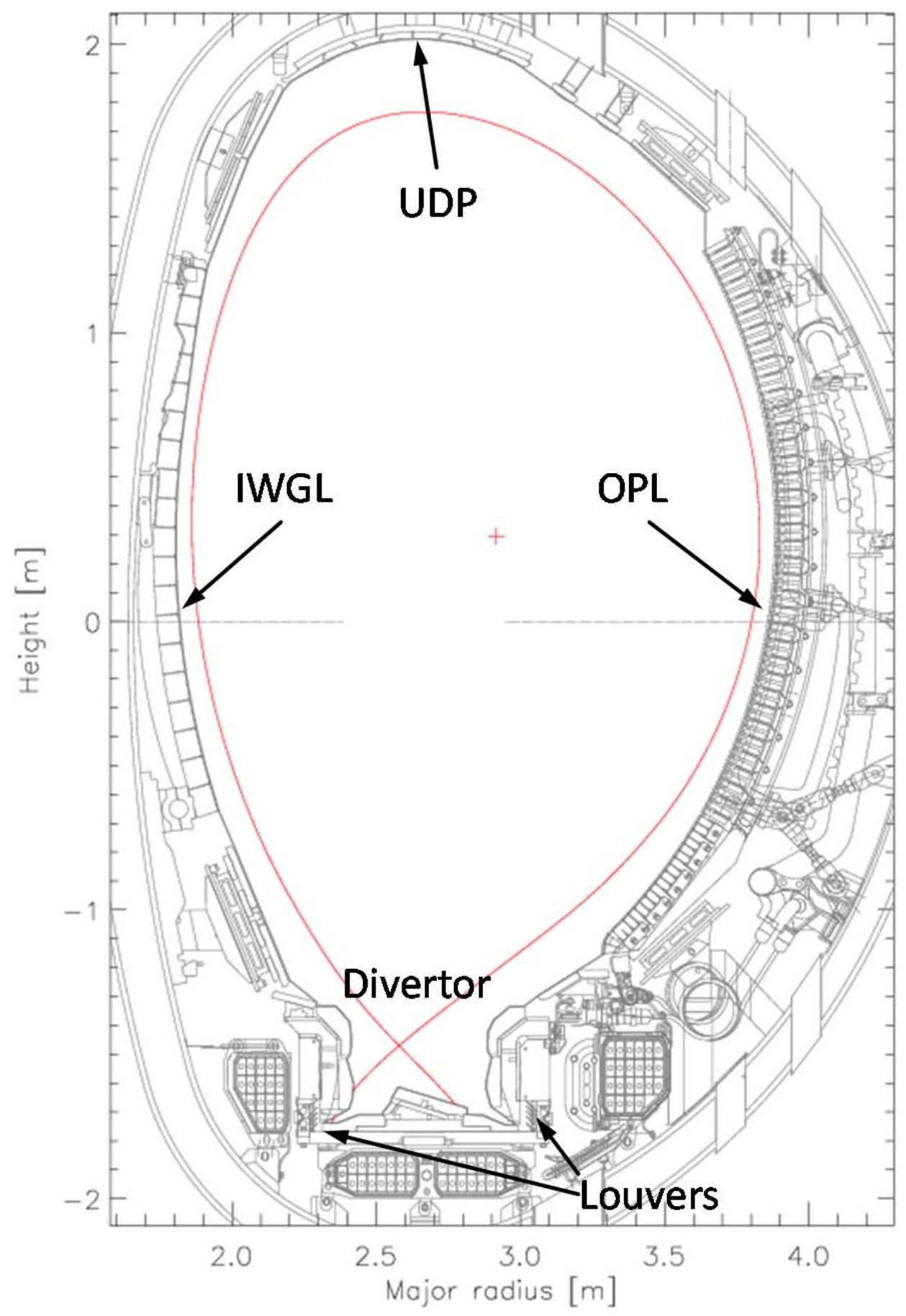

Fig. 1: Cross-section through the JET vessel during the first JET-ILW campaign 2011-2012. UDP: Upper dump plate; OPL: Outer poloidal limiters; IWGL: Inner wall guard limiters. The inner wall cladding (IWC) is between the IWGLs and recessed by a few centimeters. A typical magnetic configuration (discharge \#78649, 63.0 s) is also shown. The divertor is shown in detail in Fig. 2. 


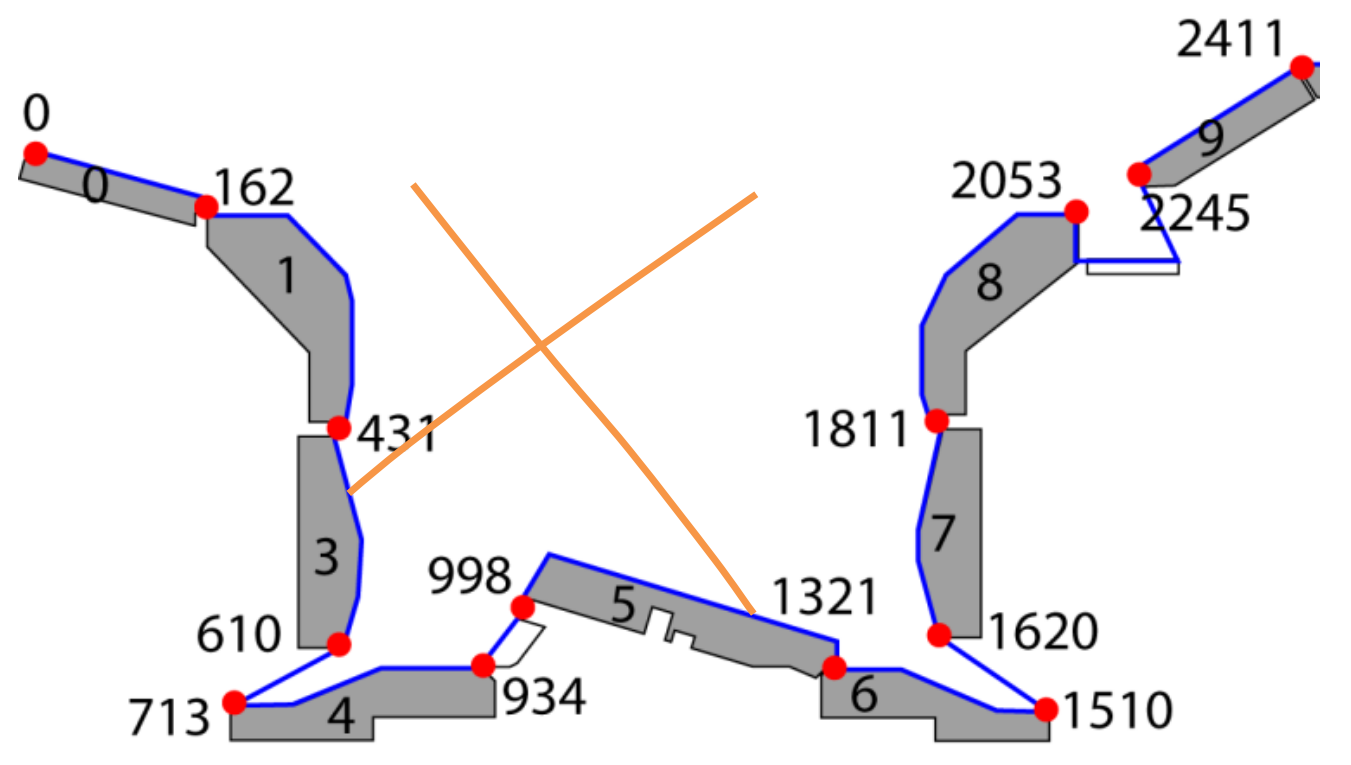

Fig. 2: JET divertor during the JET-ILW campaign 2011-2012. Tile numbers $0-9$ are indicated. The s-coordinate (in $\mathrm{mm}$ ) starts at upper left corner of tile 0 and follows the tile surfaces, some characteristic points are indicated. A rather typical magnetic configuration with inner strike point on tile 3 and outer strike point on tile 5 is also indicated. 


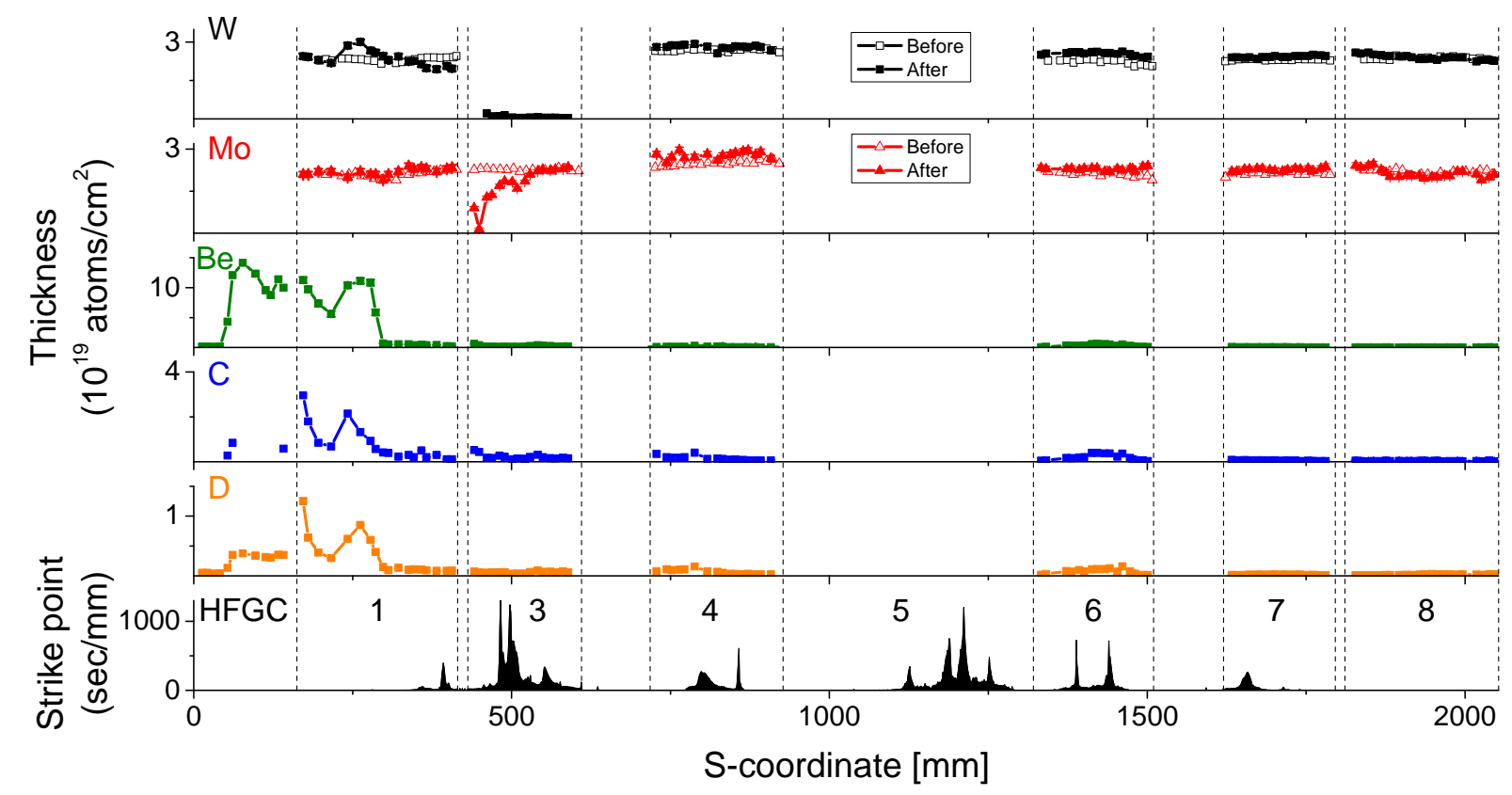

Fig. 3: Thicknesses of the $\mathrm{W}$ and Mo marker layers before and after exposure and total deposition of $\mathrm{Be}, \mathrm{C}$ and $\mathrm{D}$ on the marker tiles. A histogram of strike point positions is shown in the lowest figure. JET-ILW campaign 2011-2012. 

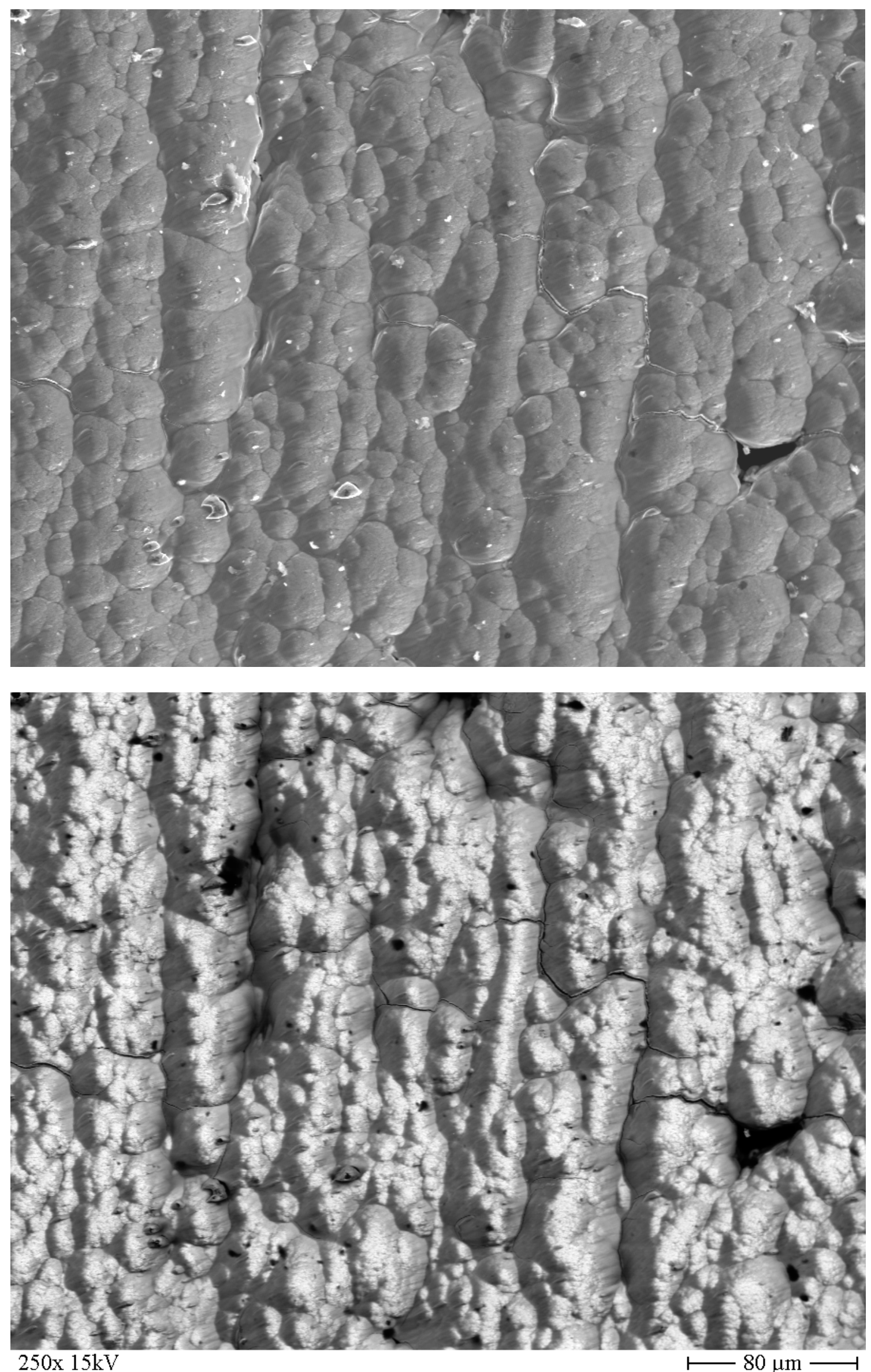
Fig. 4: Top: Scanning electron micrographs of tile 6. Top: Secondary electrons (SE); bottom: Backscattered electrons (BSE). The BSE image has a material contrast, with light elements appearing darker and heavy elements appearing brighter. 


\section{Shadow Centre Hot}

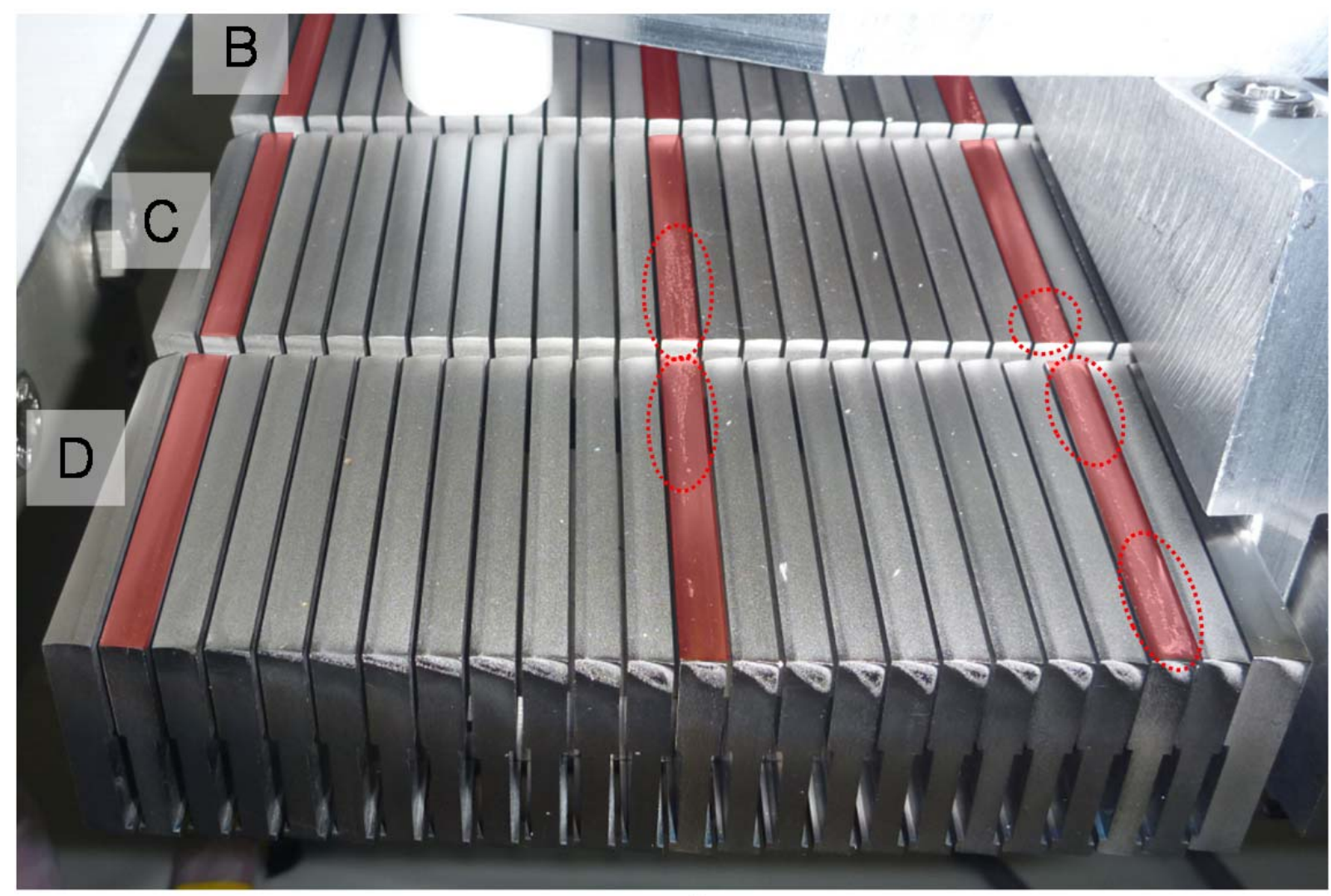

\section{$\downarrow$ To outer divertor}

Fig. 5: View of stacks B, C and D of tile 5 after removal from the JET vessel in 2012. Lamellas coated with marker layers are marked in light red. Dotted circles indicate areas with visible damage of marker layers. 


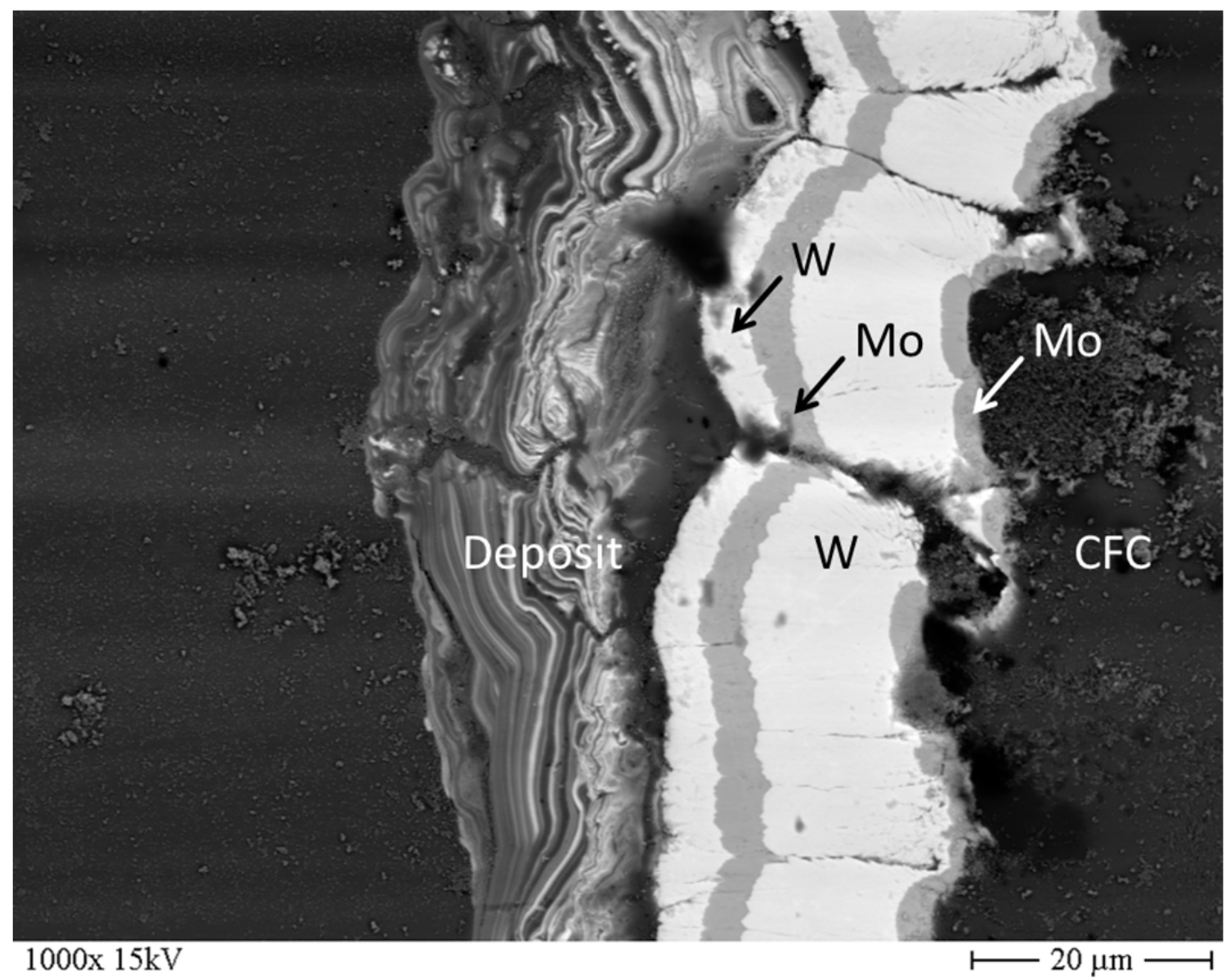

Fig. 6: Scanning electron micrograph of the deposit on tile 1 using backscattered electrons (BSE). The CFC substrate is on the right hand side, followed by a 2-3 $\mu \mathrm{m}$ thick molybdenum interlayer for improved adhesion, the 10-15 $\mu \mathrm{m}$ thick main tungsten coating, the $3 \mu \mathrm{m}$ thick molybdenum interlayer, the $3 \mu \mathrm{m}$ thick tungsten marker layer, and the rough redeposited layer consisting mainly of beryllium. The redeposited layer has a stratified structure; areas with higher tungsten concentrations appear brighter. 
Table 1: Amounts of Be, C, and D deposited on divertor tiles during the 2011-2012 discharge campaign. The amounts were determined by ion beam analysis methods, see Fig. 2, assuming toroidal symmetry.

\begin{tabular}{|l|l|l|l|l|l|l|l|l|}
\hline $\begin{array}{l}\text { Eile } \\
\text { Element }\end{array}$ & 0 & 1 & 3 & 4 & 6 & 7 & 8 & Total \\
\hline Be $(\mathrm{g})$ & 21.7 & 27.1 & 0.91 & 0.45 & 1.5 & 0.18 & 0.10 & 51.9 \\
\hline $\mathrm{C}(\mathrm{g})$ & 1.4 & 6.6 & 1.2 & 1.0 & 1.3 & 0.34 & 0.28 & 12.1 \\
\hline $\mathrm{D}(\mathrm{g})$ & 0.16 & 0.47 & 0.05 & 0.07 & 0.08 & 0.02 & 0.03 & 0.88 \\
\hline
\end{tabular}


1 Behrisch R et al 1996 J. Nucl. Mater. 233-237 673

2 Roth J et al 2009 J. Nucl. Mater. 390-391 1

3 Likonen J et al 2007 J. Nucl. Mater. 363-365 190

4 Likonen J et al 2015 in print at J. Nucl. Mater. doi:10.1016/j.jnucmat.2014.10.066.

5 Krat S et al 2015 in print at J. Nucl. Mater. doi:10.1016/j.jnucmat.2014.10.055.

6 Widdowson A et al 2013 J. Nucl. Mater. 438 S827

7 Mayer M et al 2009 J. Nucl. Mater. 390-391 538

8 Kallenbach A et al 2009 Nucl. Fusion 49045007

9 Matthews G F et al 2011 Phys. Scr. T145 014001

10 Widdowson A et al 2014 Phys. Scr. T159 014010

11 Baron-Wiechec A et al 2015 in print at J. Nucl. Mater. doi:10.1016/j.jnucmat.2015.01.038.

12 Mayer M et al 1999 J. Nucl. Mater. 266-269 604

13 Mayer M et al 1999 Phys. Scr. T81 13

14 Mayer M et al 1997 J. Nucl. Mater. 241-243 469

15 Mayer M et al 2013 J. Nucl. Mater. 438 S780

16 Krat S et al 2015 J. Nucl. Mater. 456106

17 Krat S et al 2013 J. Nucl. Mater. 438 S742

18 Mayer M et al 2007 Phys. Scr. T128 106

19 Greuner H, GLADIS-tests of carbon marker stripes for W7-X, unpublished results

20 Mayer M et al 2007 J. Nucl. Mater. 363-365 101

21 Brezinsek S 2015 in print at J. Nucl. Mater. doi:10.1016/j.jnucmat.2014.12.007.

22 Kreter A et al 2009 Phys. Rev. Lett. 102045007

23 F. Romanelli and JET EFDA Contributors 2013 Nucl. Fusion 53104002

24 Joffrin E. et al. 2015 Nucl. Fusion 54013011

25 Rimini F.G. et al. 2015 Fusion Engineering and Design, in print

26 J.W. Coenen et al. 2013 Nucl. Fusion 53073043

27 Ruset C et al 2009 Fusion Engineering and Design 841662

28 Rubel M et al 2013 J. Nucl. Mater. 438 S1204

29 Mertens Ph 2011 Phys. Scr. T145 014002

30 Krat S et al Material erosion and deposition in the JET divertor 2011-2012, in preparation for Nuclear Fusion

31 Brezinsek S et al 2013 J. Nucl. Mater. 438 S303

32 Brezinsek S et al 2015 in print at Nucl. Fusion

33 Van Rooij G J et al 2013 J. Nucl. Mater. 438 S42 
34 Ruset $\mathrm{C}$ et al this conference

35 Beal J et al this conference

36 Schmid K et al 2015 J. Nucl. Mater. 46366

37 Schmid K et al 2015 Nucl. Fusion 55053015

38 Kreter A et al 2009 Phys. Rev. Lett. 102045007 